\title{
Three-Year-Olds' Reactions to a Partner's Failure to Perform Her Role in a Joint Commitment
}

\author{
Ulrike Kachel \\ Max Planck Institute for Evolutionary Anthropology
}

\author{
Margarita Svetlova \\ Duke University
}

\author{
Michael Tomasello \\ Max Planck Institute for Evolutionary Anthropology and Duke University
}

\begin{abstract}
When children make a joint commitment to collaborate, obligations are created. Pairs of 3-year-old children $(N=144)$ made a joint commitment to play a game. In three different conditions the game was interrupted in the middle either because: (a) the partner child intentionally defected, (b) the partner child was ignorant about how to play, or (c) the apparatus broke. The subject child reacted differently in the three cases, protesting normatively against defection (with emotional arousal and later tattling), teaching when the partner seemed to be ignorant, or simply blaming the apparatus when it broke. These results suggest that 3-year-old children are competent in making appropriate normative evaluations of intentions and obligations of collaborative partners.
\end{abstract}

Humans collaborate by forming a joint goal, which then structures their individual roles. To sustain their cooperation over time, partners must then share the spoils of their collaborative effort in some mutually satisfactory way. Much research has documented that collaborating in this way-with joint goals that structure individual roles in pursuit of shared rewards - is a uniquely human form of social interaction (see Tomasello, 2014; for a review). Young children begin collaborating in this species-unique manner from around 18 months of age when they are interacting with an adult (Warneken, Chen, \& Tomasello, 2006) and from around 24 months of age when they are interacting with a peer (Brownell \& Carriger, 1991). It is also during this same age range that toddler peers begin to share the spoils of their collaborative effort in mutually satisfactory (often equal) ways (Ulber, Hamann, \& Tomasello, 2015).

We thank all the parents and children who participated in our studies. We are grateful to Gesa Volland, Moritz Kaplonek, Julia Marie Hufeld, Georg Keller, Heiko Saur, and Lara Wintzer for their help with data collection and coding, as well as to Colleen Stevens and Roger Mundry for their advice on statistics. Furthermore, we thank three anonymous reviewers for helpful comments on earlier drafts of the manuscript.

Correspondence concerning this article should be addressed to Ulrike Kachel, Department of Developmental and Comparative Psychology, Max Planck Institute for Evolutionary Anthropology, Deutscher Platz 6, 04103 Leipzig, Germany. Electronic mail may be sent to ulrike_kachel@eva.mpg.de.
Another special characteristic of human collaboration is its normative dimension, that is, acknowledgement that there are "right," culturally accepted ways of collaborating, that one is expected to honor if one enters a collaborative interaction. Quite often humans initiate a collaborative activity by agreeing to do so; for example, one individual says "Let's X" and the other says "Okay" (or just begins collaborating). Gilbert (1990) points out that this seemingly minor communicative act serves to create between collaborators a mutual obligation (see also Michael, Sebanz, \& Knoblich, 2016). That is, by making a joint commitment, the partners recognize together in their common ground that each expects the other to make sincere efforts to play her role successfully. If they have experience together in a particular collaborative activity, the common ground expectations about how each of them should fulfill her role may be quite specific: for their joint success one partner must do $\mathrm{X}$ and the other must do Y. They may also have common ground expectations about dividing the spoils in mutually satisfactory ways. The joint commitment is normative in the sense that it refers to shared standards and the failure of one partner to honor it entitles the other to protest. If the offender wishes to stay in good standing with

(C) 2017 The Authors

Child Development (C) 2017 Society for Research in Child Development, Inc. All rights reserved. 0009-3920/2017/xxxx-xxxx

DOI: $10.1111 /$ cdev. 12816 
the offended partner, he or she must accept such protest (assuming that it is legitimate) by acknowledging that his or her behavior must be changed and brought back to the shared standard. Protest is legitimate when it is based on the partners' common ground understanding of what constitutes adequate role performance or a mutually satisfactory outcome.

Young children begin to structure at least some of their collaborative activities with joint commitments from around 3 years of age (Tomasello \& Hamann, 2012). For example, when two 3-year-olds commit to a joint activity and one of them unexpectedly receives his or her reward first or receives a larger reward, that lucky child nevertheless persists until the unlucky child receives his or her reward as well or else shares some of the own excess bounty with the unlucky child (Hamann, Warneken, Greenberg, \& Tomasello, 2011; Hamann, Warneken, \& Tomasello, 2012). In contrast, if the two children enter the room and go right to the rewards, without collaboration, the lucky child just consumes her reward without a thought of the unlucky child. This shows that it is indeed the joint commitment to collaborate that creates the obligation to behave in cooperative ways. The normative force of the joint commitment is especially clear when one of the partners takes more than her fair share of the spoils of a collaborative effort, in which case the unlucky child typically protests and the lucky child almost always relents (Warneken, Lohse, Melis, \& Tomasello, 2011). If a 3-year-old child wants to break her joint commitment, they know that they must, in some sense, either ask permission or apologize for defection (Grafenhain, Behne, Carpenter, \& Tomasello, 2009).

All of these previous studies have focused on young children's joint commitments to joint goals or else their sharing of the spoils at the end. None has focused directly on children's understanding of the specific roles that each of them must play for joint success in an interdependent task, including the normative standards that govern each individual's role and so legitimate partner protest when the commitment is broken. Normally, the common ground understanding of role standards arises after partners have collaborated together in a given activity (see Fletcher, Warneken, \& Tomasello, 2012 for evidence that after just a few iterations of a collaborative activity 3-year-olds learn both their own role and also that of the partner). At that point, if one partner does not play her role in accordance with the mutually known role standard, the other partner can legitimately protest because it is clear that the defecting partner knows what he or she is supposed to do and so is breaking the commitment knowingly and intentionally. This situation is of primary interest to this study and serves as a model for our experimental condition.

On the other hand, if there has not been previous collaboration between partners, then each may wonder if the other actually knows her role standard, in which case poor performance might be reacted to not with protest but with teaching. In addition, if a role violation was unavoidable - for example, due to circumstances outside of anyone's control-then partners do not have legitimate grounds for blaming the partner who stops collaborating. These two situations serve as models for two control conditions in this study, together addressing children's abilities to discern various interpersonal nuances of a joint task. To react appropriately to what looks like a defection on the part of one partner, the other needs to: (a) understand the normative structure of a collaboration governed by joint commitment and (b) be able to infer and evaluate the specific intentions behind the defecting partner's behavior.

No prior research has examined the development of these particular abilities in young children in the context of joint commitment. However, the development of related abilities, such as understanding intentions behind other norm violations, has been investigated. Recent studies show that over the third and fourth years of life, children become increasingly skillful at understanding people's intentions behind seemingly negative behaviors and at distinguishing between intentional versus accidental transgressions. For example, English and Columbian preschoolers can discriminate between norm violations caused intentionally versus those caused by physical constraints (Nunez \& Harris, 1998). Similarly, 3-year-olds were less likely to help adults who had harmed someone intentionally (and even those who had intended but failed to harm) than those who had harmed someone accidentally (Vaish, Carpenter, \& Tomasello, 2010). In another recent study, 3- and 4-year-olds protested less when a puppet partner made a mistake under constrained conditions than when it occurred under free conditions (Josephs, Kushnir, Grafenhain, \& Rakoczy, 2016). Interestingly, the effect of the puppet's free choice was more pronounced when the mistake was framed as moral than when it was framed as conventional. A growing body of literature has also investigated children's protest, punishment, or tattling as reactions to norm transgressions, and has documented instances of normative protest and 
enforcing conventional and moral norms at 3 years of age (Ingram \& Bering, 2010; Rakoczy, Wameken, \& Tomasello, 2008; Tuncgenc, Hohenberger, \& Rakoczy, 2015; Vaish, Missana, \& Tomasello, 2011).

In this study, our goal was to explore this normative dimension of young peers' collaborative activities structured by joint commitments. That is to say, we wanted to explore young children's understanding of the normative standards governing different roles in a collaborative activity, as well as their understanding of which forms of failure to collaborate justify partner protest. We thus exposed pairs of 3-year-old peers to an apparatus that required each of them to pull in a particular way to obtain mutual rewards. Before letting the children work together, we trained one of the children (the "partner child") to play in such a way that her performance appeared substandard to the other child (the "subject child," whose reactions we measured). We manipulated the reason for which-as it appeared to the subject child-the partner child stopped collaborating in the test phase.

In one condition (the Selfish condition) children had a common ground understanding of how each of the two roles had to be played for joint success; the partner child then switched to a different game, abandoning the subject. In this condition, we expected that substandard performance by one partner would elicit protest from the other. In another condition (the ignorant condition) the children were uncertain about how well the partner knew the activity. In this condition, we expected that substandard performance might, at least on some occasions, elicit attempts at teaching the ignorant partner how to play her role. In a third condition (the accidental condition), children had a common ground understanding of the task, but then one child was unable to perform her role due to a mechanical failure of the apparatus. In this condition, we expected lower occurrences of protest or teaching.

In either condition, when protest or teaching occurred, we additionally categorized it into descriptive, personal, and normative types. We expected a higher occurrence of normative protest ("You shouldn't do that!") in the Selfish than the other conditions because the partner's behavior in that condition looked to the subject child like an intentional defection from a mutually agreed upon obligation, that is, a violation of the norm of joint commitment. We expected some normative language in the ignorant condition as well, but in the context of teaching ("This is how we should play") rather than protest because the appropriate reaction in that condition was to explain the rules of the game to the ignorant partner. We additionally coded subject children's emotional arousal and their responses to the experimenter's questions about how the game went (tattling), and we predicted that in selfish condition children would show higher arousal, signaling indignation, and higher instances of tattling and blaming the partner.

We tested 3.5-year-old children because extensive prior research suggests that by that age children not only possess the competences to act jointly and form joint commitments, but they also become increasingly skillful at understanding others' intentions, protesting against transgressors, and enforcing norms (Brownell \& Carriger, 1991; Grafenhain et al., 2009; Hamann et al., 2011; Josephs et al., 2016; Nunez \& Harris, 1998; Rakoczy et al., 2008). During the pilot phase of the study, we attempted the procedure with a younger age group (2.5- to 3-year-olds), but they were not able to follow the procedure. The criteria for the "partner" role in the dyads were especially difficult to implement with children younger than 3.5 years of age.

Importantly, in this study we measured protest between peers. Previous norm violation studies mainly investigated children's protest in interaction with adults or puppets played by adults (Rakoczy, Hamann, Warneken, \& Tomasello, 2010; Rakoczy et al., 2008; Vaish et al., 2011). However, it remains unclear to which extent children's respect for authority might influence their performance in such tasks. The peer paradigm allows a clearer insight into children's understanding of joint commitment as they are tested in interaction with equals.

\section{Method}

\section{Participants}

Participants were 144, 3.5-year-old children ( $M=41.6$ months, $S D=1.3 ; 72$ boys; $)$ of heterogeneous socioeconomic backgrounds (predominantly middle class and Caucasian), attending preschool in a medium-sized European city. Prior to the study, parents had given informed consent for their children's participation. Children were tested in samesex dyads. In each dyad only one child was an actual subject; the second child (hereafter the partner) was trained as a confederate but remained naïve to that. This resulted in $N=72$ subject children (36 boys) and $N=72$ partner children (36 boys). Six additional dyads were tested but excluded from analyses due to experimenter $(N=2)$ or confederate $(N=4)$ error. A confederate 
error was when the partner child deviated from his or her instructions in both test trials; for example, started pulling on the rope in the condition where he or she was supposed to open a box instead. If the partner's behavior deviated during only one of the two test trials, the other test trial was included in the analyses (this was the case in 10 dyads). Dyads were trained and tested in a quiet room in their preschool in a session lasting approximately $60 \mathrm{~min}$. Data collection took place between November 2014 and May 2015.

\section{Materials and Design}

A modified version of the apparatus used by Hamann et al. (2011); Hamann, Bender, and Tomasello (2014) was used (see Figure 1). To obtain two marbles (one for each player), both partners had to pull on a rope together to move a block toward the two marbles. Pulling on the rope alone as well as accessing both ends of the rope was impossible, which created the necessity for collaboration. When two partners pulled together, the block moved and pushed the marbles from their platform and they rolled toward two separate openings where the players could retrieve them. The children could then insert their marbles into an opening in an elephant-shaped "jingle machine" behind the apparatus as a reward. The game was presented to them as "feeding the elephant."

Our modification of the task was that as children confronted the task, both ropes were not immediately accessible but had to be retrieved from the backside of the apparatus by moving a detachable handle (with the rope magnetically attached to it) along a zigzag-shaped track. Only if both children moved their handles with the rope to the front, could the joint pulling begin. In all three conditions the subject children learned that this was the way to play the game. Partner children, trained

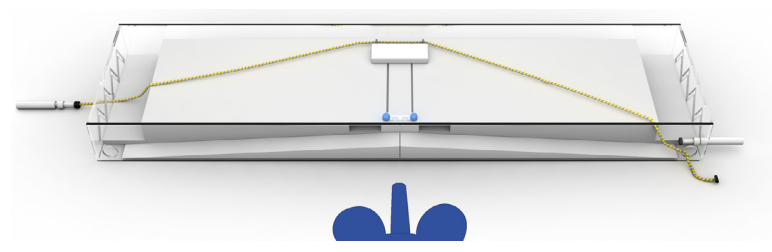

Figure 1. Apparatus of the main game. The ropes can be attached to the handles. The handles have to be moved along the zigzag-shaped tracks on the sides. The subject (here on the right side) takes out the rope in the front to pull. The partner child (on the left side) takes out the handle in the middle of the zigzagshaped track through an additional hole. separately, learned the basics of this task but with variations in the different conditions.

Participants for each dyad were randomly selected among children who were available (and whose parents had given informed consent) at the preschool on the day of testing. Then dyads were randomly assigned to the three experimental conditions (Selfish; Ignorant; Accidental); within each dyad, children were randomly assigned to their role in the dyad (subject; partner). Each dyad received two test trials in one of three conditions in a between-subjects design.

\section{Procedure}

Dyads of children were picked up in their classroom and brought to the test room by the lead experimenter (E1). After a brief familiarization, each child individually received three training trials with E1 while the other child was outside with an assistant experimenter (E2). The subject child in all three conditions learned how to play the collaborative version of game: At each trial, the subject and E1 sat by their respective sides of the apparatus; they each moved their handle along the zigzag track to retrieve the rope; then they pulled together, each on their end of the rope, to get the marbles and feed them to the elephant. The training ensured that the subject understood the interdependent aspect of the game, that is, that one partner could not pull and retrieve the rewards if the other did not participate.

The partner child received a different individual training from E1 depending on the respective condition.

\section{Partner Training for Selfish Condition}

In this condition, the partner child was trained to play the game differently so that during the test phase his or her performance looked like defection from collaboration to the subject child (the partner was unaware of that). The game presented by E1 to the partner involved detaching the handle (that could also be used for pulling) from the apparatus and using that handle to open an individual colorful box and retrieve stickers from it. The box (subsequently the "selfish box") was placed on the partner's side of the apparatus. It contained a red sticker and a sheet of paper with a drawing of an elephant. During training the partner child was told that the game was to retrieve the sticker and place it on the paper elephant's belly. That way, the expression "feeding the elephant," subsequently used by E1, made sense for both children, although 
it involved different actions for each of them. For the partner child, "feeding the elephant" involved detaching the handle of the apparatus midway along the zigzag path (facilitated by an additional hole in the side panel) and using that handle to open the selfish box. During test phase, from the subject child's perspective, such actions on the part of the partner looked like abandoning the joint pulling game in the middle, that is defecting, because the subject could not pull on the apparatus alone.

In addition, in this condition, subject children also received their own selfish box with a sticker (but without a paper elephant), and during training they experienced using the handle for getting the sticker. That ensured that during the test: (a) the subject child understood what the partner was doing, and (b) the partner saw that the subject also had such a box and thought that they were playing the same game. The subject child experienced the box at the beginning of the training; then E1 proceeded with teaching him or her the joint pulling game. In all the following training trials and during

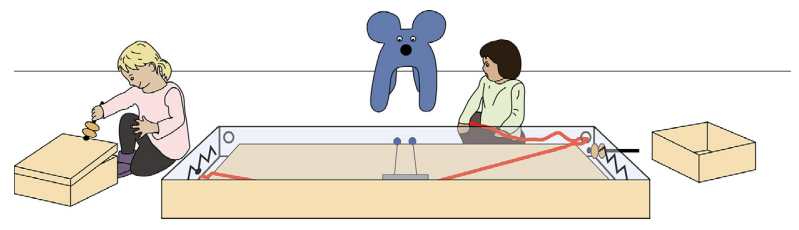

A

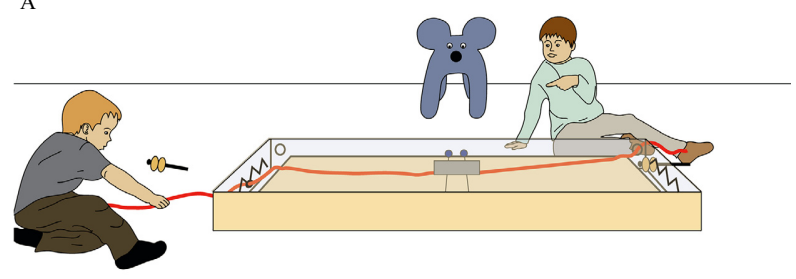

B

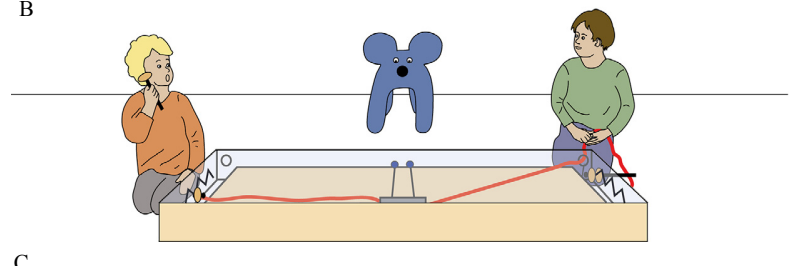

C

Figure 2. The partner behavior in the three conditions. The partner is depicted on the left side and the subject on the right side. In all three conditions the partner starts by moving the handle along the zigzag-shaped track, until he or she reaches the hole in the middle of the track. In the selfish condition (2A) the partner removes the handle through this hole to open the selfish box; in the ignorant condition (2B) the partner removes the handle and rope through this hole to pull on the side; and in the accidental condition $(2 \mathrm{C})$ the rigged handle breaks right next to the hole. the test trials the subject's selfish box remained already open and was empty (see Figure 2 A).

\section{Partner Training for Ignorant Condition}

In this condition, to make the partner appear incompetent but willing to collaborate, the partner child was trained to operate the apparatus in a way (involving pulling on the side) that worked during training but would not work later during the test. The subject child was trained in the correct way to use the ropes (pull from the front) but was also exposed on one training trial with E1 doing it the way that the partner would later do it (unsuccessfully pulling from the side). Thus, after the training trials, the partner child knew only how to pull (incorrectly) on the side and the subject child knew how to pull on the front and that pulling on the side would not work (see Figure 2 B).

\section{Partner Training for Accidental Condition}

In this condition the partner child was supposed to be unsuccessful due to a reason outside of her control. During the individual training phase, each child was trained how to pull correctly together with E1 twice. On the third training trial, E1 experienced and commented on the "accidental breaking" of the handle of the apparatus on her side to familiarize both children with the situation. For that trial, the handle was rigged and broke in the middle of the zigzag path. The apparatus was then rigged in the same way on the partner's side during test trials (see Figure $2 \mathrm{C}$ ).

\section{Test Trials}

After both children had received their training, the first test trial followed. E1 gathered the two children and announced that they now could play the game together, without E1. To create a joint commitment, E1 took both children by their hands and confirmed that they would play the game together now. Both the subject and the partner had to agree to that in the presence of each other by saying "yes," "okay," or nodding. Then E1 accompanied the subject inside the test room and reminded him or her about the ultimate goal of the joint game (feeding marbles to the elephant). To ensure that the subject paid attention to the partner's actions, E1 commented on the partner either in a confident way ("He knows how to play the game") in the selfish and accidental conditions or in an uncertain way ("I'm not sure if he knows how the game really 
goes") in the ignorant condition. After that, E1 brought the partner into the room and left the children alone until the trial ended. After the first test trial, each child separately received an additional training trial with E1. This trial was added to remind them of their individual ways to play the game and to encourage them to proceed in the same way with the second test trial. Then the second test trial followed, identical to the first test trial.

During each test trial, we measured subjects' reactions to the partner's failure (e.g., with protest, teaching, etc.) as well as their tattling behavior after each test trial. The subjects had $20 \mathrm{~s}$ to react from the time they noticed the failure (if they started to react at exactly $20 \mathrm{~s}$, they were allowed to finish). If the subject did not react, the test trial was ended after $20 \mathrm{~s}$, at which point E2 entered the test room and called the partner to come out. Then E1 entered the test room, giving the subject the opportunity to tattle about what happened. If the subject did not spontaneously begin to tattle, E1 asked a series of three questions: (a) "Did it work?" (b) "Did you feed the elephant?" and (c) "Why did you not feed the elephant?" How the game proceeded in each of the three conditions is depicted in Figure 2. At the end of the procedure, E1 fixed the apparatus for a final happy-end trial (not included in the analyses) in which children successfully collaborated and received their marbles.

Our procedure script included a possibility of ending the testing early in case either of the children refused to continue, was distracted, or was upset. However, the latter never happened. All the children who started playing the game were willing to play in the second trial and in the happy-end trial.

\section{Coding and Reliability}

The main measure was the subject's reactions to the partner's behavior during the test phase when the two children were left alone to "play the game." The subject's language was transcribed and coded for protest and teaching utterances of three different types: (a) normative language, (b) personal language (directing the partner without normative language), and (c) descriptive language (utterances without normative or personal language that contained descriptive relevance to the joint game). We used a modified version of the coding scheme from Göckeritz, Schmidt, and Tomasello (2014). Utterances were coded as protest if they indicated that the subject's intention was to stop the partner's current approach to playing the game and as teaching if they indicated that the subject's intention was to inform the partner about the right way to play the game (see Table 1 for descriptions and examples).

In addition, the subject's emotional arousal during the test phase was measured on a scale between 0 and 3: (0) no behavioral change in the subject child; (1) subject child shows slight signs of irritation; (2) subject child shows signs of agitation, frustration, talks louder than previously; and (3) subject child shows signs of extreme agitation, frustration, or anger, screams at the partner. Following each test trial, spontaneous and elicited tattling behavior of the subjects was coded as one of the following three categories: (a) tattling that the goal was not reached but without blaming something or someone, (b) tattling with blaming the apparatus, or (c) tattling with blaming the partner (see Table 1 for examples).

All of the sessions were videotaped and coded by the first author. To establish reliability, a naïve coder who was blind to the conditions and the hypotheses of the study coded a randomly selected sample of $20 \%$ of the data for each measure in each condition. The two coders were in very good to excellent agreement (Cohen's $\kappa$ ranging between 0.71 and 1$)$.

\section{Results}

We analyzed subjects' protests and teaching separately, focusing on the effect of condition for each type of reaction. We also looked at children's tattling and emotional arousal in the three conditions. For each analysis we ran a GLMM (generalized linear mixed model) (Baayen, Davidson, \& Bates, 2008). To establish the significance of the effect of the test predictors as a whole, we ran a likelihood ratio test (Dobson \& Barnett, 2008) comparing the full model with a null model (Forstmeier \& Schielzeth, 2011). Model stability was good, and neither collinearity nor overdispersion was an issue in the models. There was no effect of gender in any of the models. For each subject, we used both trials in the analyses, unless one of the trials was unusable (typically due to the partner deviating from the scripted behavior) in which case we only included the correctly acted-out trial (this was the case in 10 dyads).

\section{Protest}

In the main model we analyzed the proportion of trials (out of the total number of usable trials) in which subjects protested, as well as which type of 
Table 1

Examples of Utterances for Each Type of Protest, Teaching, and Tattling

\begin{tabular}{|c|c|c|}
\hline Category & Description & Examples \\
\hline Protest & $\begin{array}{l}\text { Utterances that indicated that the subject's intention was to stop the } \\
\text { partner's current approach to playing the game }\end{array}$ & See below, for the different types of protest \\
\hline $\begin{array}{l}\text { Normative } \\
\text { protest }\end{array}$ & $\begin{array}{l}\text { Utterances contain normative language: must not, have to, shouldn't, } \\
\text { wrong, false, etc. }\end{array}$ & $\begin{array}{l}\text { "that's wrong," "you're not allowed to } \\
\text { do that," "no, you have to. ..," }\end{array}$ \\
\hline $\begin{array}{c}\text { Personal } \\
\text { protest }\end{array}$ & $\begin{array}{l}\text { Utterances that are specifically directed at the stooge and his behavior } \\
\text { without normative language, negative imperatives, basic protest, } \\
\text { blameful interjections }\end{array}$ & $\begin{array}{l}\text { "don't do that," "stop it," "no not like that," } \\
\text { "hey" }\end{array}$ \\
\hline $\begin{array}{l}\text { Descriptive } \\
\text { protest }\end{array}$ & $\begin{array}{l}\text { Descriptive utterances that do not contain normative language or address } \\
\text { the partner but have relevance to the game }\end{array}$ & $\begin{array}{l}\text { "it broke," "you pull on the side," } \\
\text { "you took it out" }\end{array}$ \\
\hline Teaching & $\begin{array}{l}\text { Utterances that indicated that the subject's intention was to inform the } \\
\text { partner about the right way to play the game, utterances accompanied } \\
\text { by demonstrations of the right way to play the game }\end{array}$ & See below, for the different types of teaching \\
\hline $\begin{array}{l}\text { Normative } \\
\text { teaching }\end{array}$ & Utterances contain normative language: must, have to, should, right, etc. & $\begin{array}{l}\text { "it goes like this," "this is how you play } \\
\text { it right," "you have to get it to the front" }\end{array}$ \\
\hline $\begin{array}{l}\text { Personal } \\
\text { teaching }\end{array}$ & $\begin{array}{l}\text { Utterances that are specifically directed at the stooge and his behavior } \\
\text { without normative language, positive imperatives }\end{array}$ & $\begin{array}{l}\text { "do this," "pull," "get your rope," "like this," } \\
\text { "heave-ho" }\end{array}$ \\
\hline $\begin{array}{l}\text { Descriptive } \\
\text { teaching }\end{array}$ & $\begin{array}{l}\text { Descriptive utterances in which the subject describes the action the } \\
\text { partner should do without normative or imperative vocabulary. }\end{array}$ & $\begin{array}{l}\text { "further," "up and down, up and down," } \\
\text { "to the front" }\end{array}$ \\
\hline Irrelevant & Utterance that have no relevance to the game & "blue is a nice color" \\
\hline $\begin{array}{l}\text { Neutral } \\
\text { tattling }\end{array}$ & $\begin{array}{l}\text { Tattling utterances communicating that the game did not work but } \\
\text { without blaming someone or something (descriptive) }\end{array}$ & "we didn't do it," "you have to help me" \\
\hline $\begin{array}{l}\text { Apparatus } \\
\text { tattling }\end{array}$ & $\begin{array}{l}\text { Tattling utterances communicating that the game did not work, blaming } \\
\text { the apparatus }\end{array}$ & "it/this broke," "broken" \\
\hline $\begin{array}{l}\text { Partner } \\
\text { tattling }\end{array}$ & $\begin{array}{l}\text { Tattling utterances communicating that the game did not work, blaming } \\
\text { the partner child }\end{array}$ & $\begin{array}{l}\text { "she took the handle out," "Maria broke it," } \\
\text { "Paul doesn't know how to do it" }\end{array}$ \\
\hline
\end{tabular}

protest they used. The GLMM thus included condition, protest type (descriptive; personal; normative), the interaction of condition and protest type, and gender as fixed effects, and dyad-ID as a random effect. To account for some dyads having a different number of trials, we also included the logtransformed number of trials as an offset term into the model. Overall, the full model provided a significantly better fit compared to the null model $\left(\chi^{2}=49.72, d f=8, p<.001\right)$. More specifically, there was an effect of condition $\left(\chi^{2}=32.77, d f=2\right.$, $p<.001)$ indicating that children protested in a higher proportion of trials in the selfish condition than in both the accidental condition (estimate $\pm S E=1.62 \pm 0.32, z=5.11, p<.001)$ and the ignorant condition (estimate $\pm S E=0.95 \pm 0.23$, $z=4.05, p<.001)$. There was a trend for an interaction of condition and protest type $\left(\chi^{2}=8.77, d f=4\right.$, $p<.067$ ), suggesting that the main effect of condition should be interpreted in this light (see Figure 3). Analyzing the effect of condition separately for each protest type revealed that subjects used more normative protest in the selfish condition than in the accidental condition (estimate $\pm S E=-2.34 \pm 0.74, z=-3.16, p<.01)$ and the ignorant condition (estimate $\pm S E=-1.07 \pm$ $0.42, z=-2.57, p<.05)$. They also used more personal protest in the selfish condition than in the accidental condition (estimate $\pm S E=2.07 \pm 0.53$, $z=-3.89, p<.001)$ and the ignorant condition (estimate $\pm S E=-1.26 \pm 0.36, z=-3.45, p<.001)$. As hypothesized, there was no significant difference between conditions in descriptive protest.

\section{Tattling}

We were also interested in the proportion of trials with different types of tattling. The main model consisted of condition, tattling type (neutral, apparatus blaming, and partner blaming), the interaction of condition and tattling type, and gender as fixed effects, and dyad-ID as a random effect (and the log-transformed number of trials as an offset term). Overall the full model provided a significantly better fit for the data than the null model $\left(\chi^{2}=46.19\right.$, $d f=8, p<.001)$. Further analyses revealed a significant interaction between condition and tattling type $\left(\chi^{2}=38.76, d f=4, p<.001\right)$, indicating that subjects blamed the partner more in the selfish condition than in the ignorant condition (estimate $\pm S E=$ 
Descriptive Protest

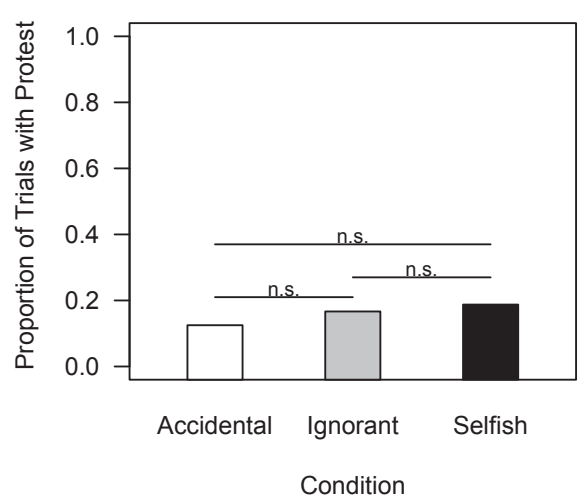

Normative Protest

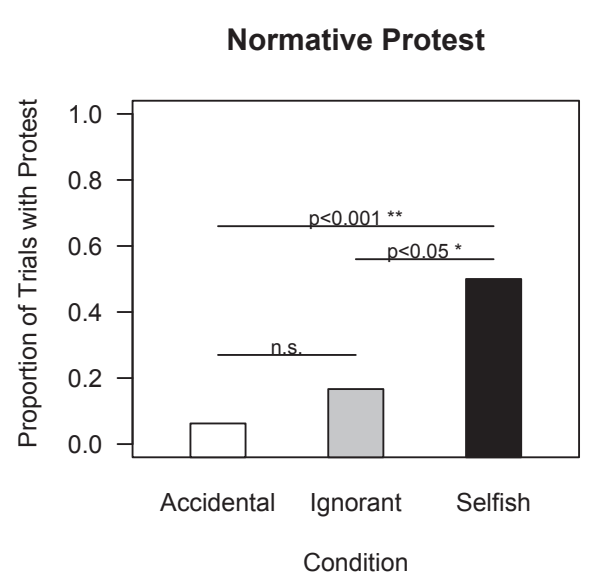

Personal Protest

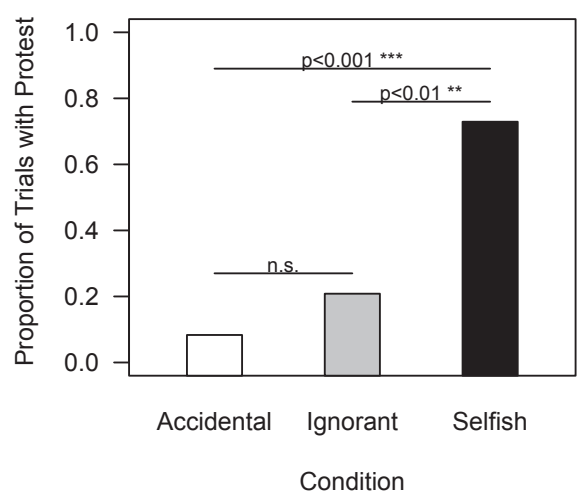

Figure 3. Proportion of trials with different types of protest as a function of condition. ${ }^{*} p<.05,{ }^{* *} p<.01,{ }^{* * *} p<.001$.

$0.76 \pm 0.37 z=2.03, p<.05)$. There was also a trend for subjects to blame the partner more in the selfish condition than in the accidental condition (estimate $\pm S E=0.65 \pm 0.37 z=1.74, p=.08$ ). In contrast, blaming the apparatus was present more in the accidental condition than in the selfish condition (estimate $\pm S E=-1.76 \pm 0.44 \quad z=-3.98$, $p<.001)$ and more in the ignorant condition than in the selfish condition (estimate $\pm S E=-1.43 \pm$ $0.45 z=-3.17, p<.01)$. Neutral statements without blame occurred more in the selfish condition than in the accidental condition (estimate $\pm S E=1.21 \pm 0.47$ $z=2.59, p<.01)$ and more in the ignorant condition than in the accidental condition (estimate $\pm S E=$ $1.28 \pm 0.46 z=2.8, p<.01$; see Figure 4 ).

\section{Emotional Arousal}

Supporting this analysis, we also investigated children's emotional arousal in a similar manner. Once again, results revealed a significant effect of condition $\left(\chi^{2}=25.84, d f=2, p<.001\right)$, indicating that children were significantly more aroused in the selfish condition than in both the accidental condition (estimate $\pm S E=1.36 \pm 0.29, z=4.71, p<.001$ ) and the ignorant condition (estimate $\pm S E=0.42 \pm$ 0.20, $z=2.01, p<.05)$, and more in the ignorant condition than in the accidental condition (estimate $\pm S E=-0.94 \pm 0.3, z=-3.15, p<.01$; see Figure 5).

\section{Teaching}

In the main model for teaching we analyzed the proportion of trials (of 2) in which subjects engaged in teaching behavior as well as which type of teaching they used. The GLMM thus included condition, teaching type (descriptive, personal, and normative), the interaction of condition and teaching type, and gender as fixed effects, and dyad-ID as a random effect. Again, to account for some dyads having a different number of trials, we also included the log-transformed number of trials as an offset term into the model. Overall the full model 
Neutral Tattling

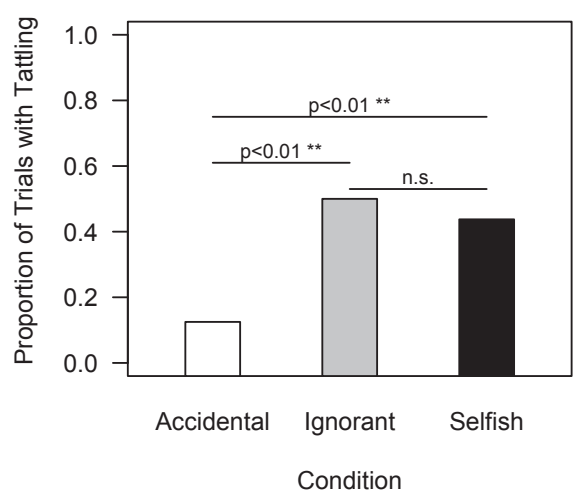

Partner Tattling

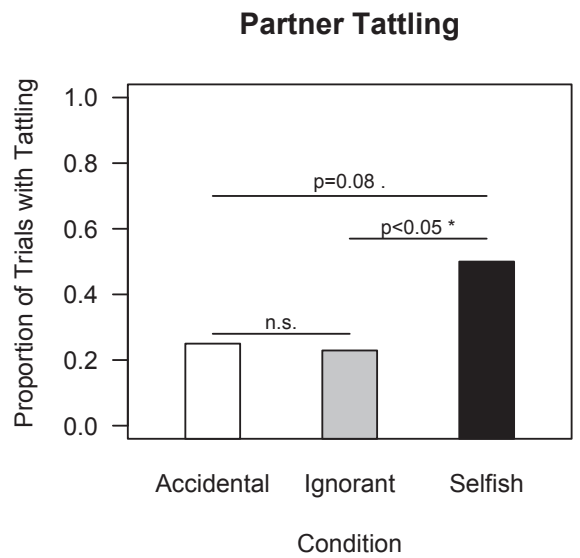

Apparatus Tattling

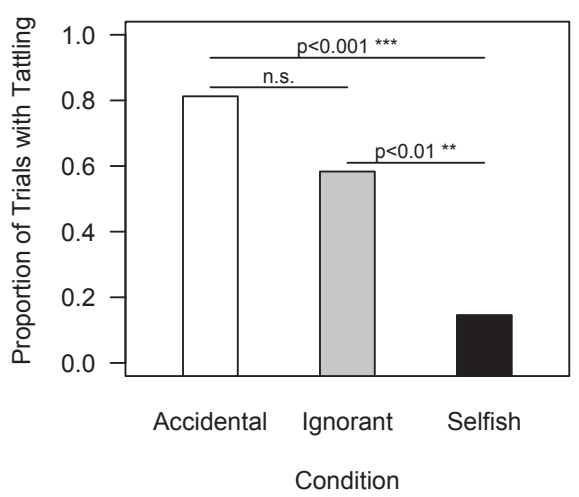

Figure 4. Proportion of trials with different types of tattling as a function of condition. ${ }^{*} p<.05,{ }^{* *} p<.01,{ }^{* * *} p<.001$.

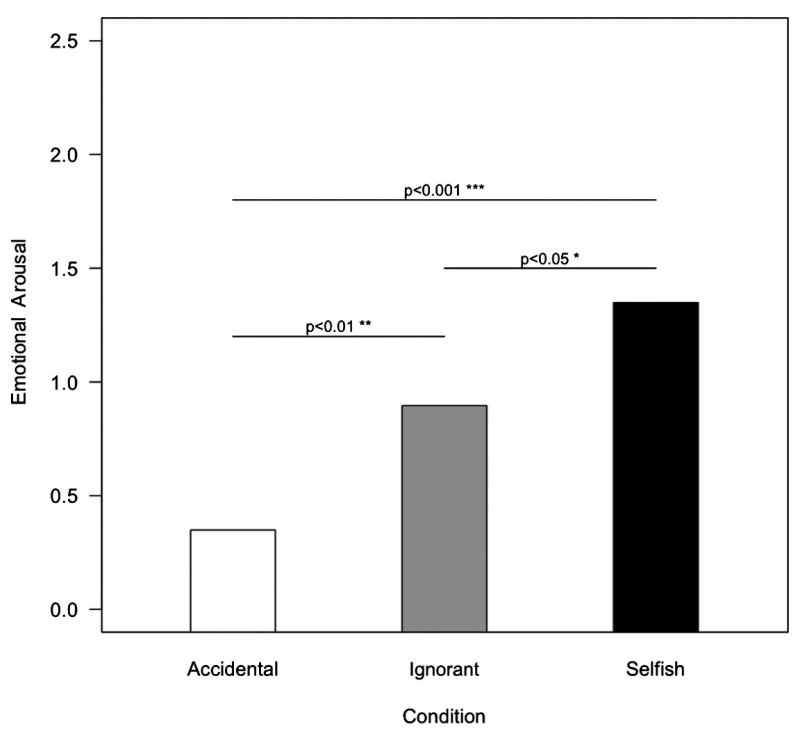

Figure 5. Subjects' emotional arousal as a function of condition. ${ }^{*} p<.05,{ }^{* *} p<.01,{ }^{* * *} p<.001$. provided a significantly better fit as compared to the null model $\left(\chi^{2}=29.23, d f=8, p<.001\right)$. Further analyses revealed an effect of condition $\left(\chi^{2}=26.73\right.$, $d f=2, p<.001)$ indicating that children taught significantly more in the ignorant condition than in both the accidental condition (estimate $\pm S E=-2.19 \pm 0.51 z=-4.29, p<.001)$ and the selfish condition (estimate $\pm S E=-1.03 \pm 0.33$, $z=-3.13, p<.01)$ and more in the selfish condition than in the accidental (estimate $\pm S E=1.16 \pm 0.55$, $z=2.01, p<.05)$. There was no interaction between condition and teaching type $\left(\chi^{2}=1.32, d f=4\right.$, $p=.86$; see Figure 6).

\section{Discussion}

The current results suggest that 3-year-old children understand the basic normativity involved in collaborative activities structured by a joint commitment, and that they react in basically adult-like 


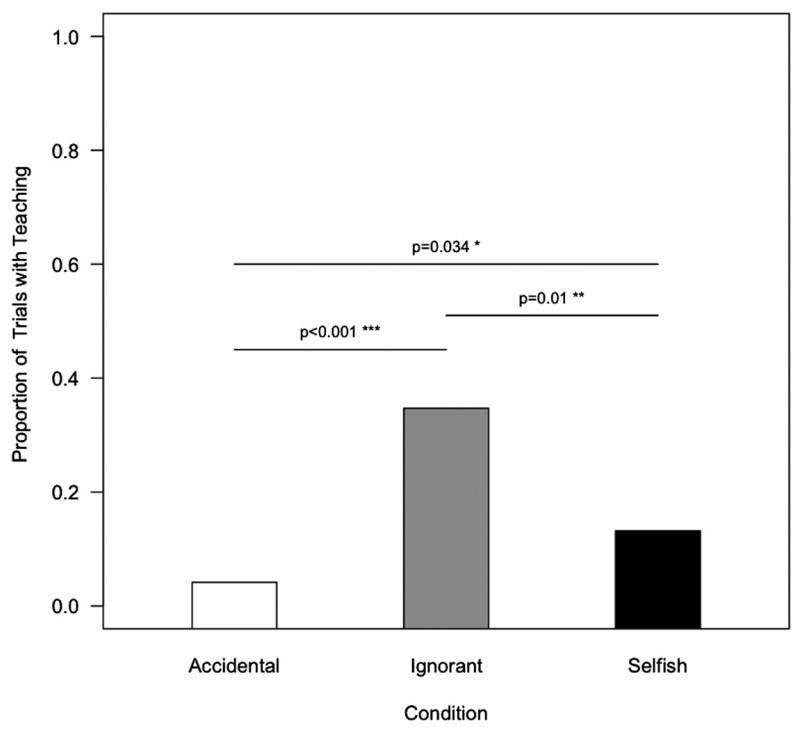

Figure 6. Proportion of trials with teaching (all types of teaching combined) as a function of condition. ${ }^{*} p<.05,{ }^{* *} p<.01$, ${ }^{* * *} p<$ .001 .

ways to partner failure (Mathew \& Boyd, 2014). That is to say, 3-year-old children act in socially and normatively appropriate ways when their collaborative partner fails to execute her collaborative role successfully - that is, fails to live up to her side of a joint commitment-for various reasons. When their partner seemingly defected intentionally, they protested with relatively high emotional arousal and verbally blamed her for her failure. When their collaborative partner was ignorant of how to play her role, they protested and blamed less, but rather attempted to teach. When the apparatus failed, they behaved very differently, protesting against the partner very little, showing low emotional arousal, and verbally blaming the apparatus. Arguably, these are the kind of reactions that could be expected of a competent moral agent (or at least a competent normative agent) who treats her collaborative partner as another competent moral agent (Darwall, 2006).

This conclusion is supported further by the interaction between the condition and protest type. Children protested significantly more with normative protest and personal protest in the selfish condition than in the ignorant and the accidental conditions. However, there was no difference between conditions in the level of descriptive protest. Although children are naturally frustrated and react with language that has descriptive relevance to the joint game if the task is interrupted for any reason, they react stronger, use more normative language (normative protest), and directly address their interaction partner (personal protest) if they think the partner intentionally broke the joint commitment. The outcome of an unsuccessful collaboration -inability for the subject child to receive his or her rewards - was the same in all three conditions, but their reactions were drastically different; thus, the children in our study correctly inferred and appropriately addressed the underlying intentions of their interaction partners.

More specifically, children's behavior in this study was driven by their cognitive competencies for distinguishing: (a) the intentions of the partner (in the selfish and accidental conditions) and (b) the knowledge versus ignorance of the partner (in the ignorant condition). Distinguishing intentional from accidental actions is clearly within the competence of 3-year-old children, and indeed an ability that even toddlers possess (Carpenter, Akhtar, \& Tomasello, 1998; Meltzoff, 1995). In addition, previous research has also shown that children of this age are able to distinguish knowledgeable from ignorant individuals (e.g., Moll, Carpenter, \& Tomasello, 2007; ONeill, 1996). The most reasonable interpretation, then, is that the children were applying well-known social-cognitive abilities but in a morally relevant context.

In terms of protest, Josephs et al. (2016) found that in a third-party paradigm, 3- and 4-year-old children protested more when an actor transgressed intentionally than when he or she produced the same outcome but had no ability to choose her actions. Interestingly, the children distinguished more between freely performed mistakes and mistakes that occurred under constraints when the situation was framed as a moral transgression, as opposed to a conventional transgression. This result is generally consistent with the current results where children protested more against a defecting partner who acted seemingly freely than a partner who defected unintentionally. The consistency of our results with the moral condition in the Josephs et al. (2016) study contributes to our interpretation of children's reactions as morally relevant. Tuncgenc et al. (2015) did not find 3-year-olds protesting differently toward an agent's intentional versus unintentional transgressions: the children protested in both cases, whereas in our study children protested less if the failure was accidental. But in their study unintentional meant constrained from acting at all (hands tied), possibly making it ambiguous what the intentions could have been had the agent been free to act. In contrast, in this study in the accidental condition the partner child was clearly uninvolved in the accident (the apparatus broke). 
The nature of the tasks used in Tuncgenc et al. (2015) versus Josephs et al. (2016) and this study may also have contributed to the differences in results, as the "daxing" paradigm from Tuncgenc et al. (2015) falls into a conventional, as opposed to moral, transgression category.

An interesting comparison in this regard is the study of Cushman, Sheketoff, Wharton, and Carey (2013). They found that 4- to 8-year-old children showed a greater concern with the outcome of an action versus intent behind an action in their thirdparty punishment. The theoretical idea is that children (indeed persons of all ages) base their partner preferences on intent (preferring people with good intentions, as in Vaish et al., 2010, and Dunfield \& Kuhlmeier, 2010), but they punish on the basis of outcome (punishing those who cause harm whatever their intentions). The results from Cushman et al. (2013) might be seen as discrepant with ours, in which children took into account intent, and not outcome, in deciding whether to protest or teach. This discrepancy may be due to the difference between uninvolved third-party reactions and more salient second-personal reactions, and perhaps the special role that joint commitment plays in human social lives from early on. The case where $I$ am the victim and you directly and intentionally violate your commitment to me may thus elicit more protest.

Prior research suggests that toddlers may already be able to act as second-personal moral agents in the sense of behaving prosocially toward specific other individuals (Tomasello \& Vaish, 2013). This study demonstrates that by 3.5 years of age, children understand the normative dimension of human action, involving impersonal normative standards and the obligation to live up to them when acting interdependently with others. When others violate the normative standards applying to them, the appropriate response is some type of normative protest. Protest manifests a respectful attitude toward a cooperative partner, as it assumes that he or she is a competent agent who knows what he or she did wrong and is able to self-correct as needed. By 3.5 years of age, children's understanding of normative standards incorporates a nuanced appreciation of intentionality, which leads children to respond differently and appropriately in situations reflecting a partner's differential intentions with regard to the joint obligation. The children thus not only act as second-personal normative agents but also understand and treat others as such.

The current design investigating young children's joint commitment with a peer also tapped into young children's emotional involvement with a collaborator. Thus, when their partner defected intentionally, the children protested in an emotionally involved way, perhaps expressing the most basic second-personal emotion of resentment for being treated poorly by a supposedly cooperative partner (Strawson, 1974). This justified or legitimated their assessment of moral blame and so their protest (Smith, 2013). Importantly, this protest was quite often of a normative nature: it is not just that I do not like it when you do that but that one should not do that. Quite often the protest was not specifically about the transgression-it was more like "Hey, what are you doing?" - which treats the partner as a second-personally cooperative agent who (a) knows what he or she has done wrong, and (b) knows what to do to correct it.

In addition, this study is the first to show that 3year-old children understand that an ignorant partner is not responsible for the outcome of her actions in the context of joint commitment. They protest minimally when an ignorant partner does not do what they know they are supposed to do; instead, they attempt to teach them so as to turn their ignorance into knowledge, which presumably will result in more successful cooperative behavior. Koymen, Schmidt, Rost, Lieven, and Tomasello (2015) looked at some of the discourse features involved in young children's instruction versus protest, but children in that study did not need to distinguish different types of partners or violations. Although it is sometimes said that "ignorance is no excuse," the children in this study seemingly believed that it is. Interestingly, children also engaged in teaching more in the selfish condition than in the accidental condition. This might reflect that, in comparison to the accidental condition where there is nothing left to be done after the apparatus has broken, in the selfish condition the game was not yet lost completely. As opposed to protest, teaching is a good way to get the partner back on track with goodwill.

The current results thus add to a growing body of literature that even 3-year-old children have a good bit of normative competence. Beginning already in infancy, young children have an intrinsic motivation to help others in need (see Hepach, Vaish, \& Tomasello, 2013, for a review), thus displaying the morally relevant emotion of sympathy toward needy others. This study demonstrates, in addition, an emerging sense of respect, fairness, and obligation in the sense that an individual who jointly commits to a cooperative activity has an obligation to treat the partner as an equally deserving peer-by fulfilling the collaborative role to which he or she has committed. Obviously, children 
still have much to learn about many aspects of adult normativity and morality, including the many nuances of intentionality, ignorance, and the resulting assignment of blame, and they only know a small subset of the moral norms characteristic of their culture. But the fundamental skills and motivations for engaging with others directly as normative agents who should be treated with sympathy and fairness seem to be in place by 3 years of age.

Importantly, unlike much of previous research on joint action and intention understanding that has used adult partners, puppets manipulated by adults, or hypothetical situations presented by adults, children in this study interacted with their peers. Training participants' age mates as naive confederates allowed to test children's competences under very conservative conditions, without adult guidance, scaffolding, or attention management. Critically for our theoretical perspective, forming and acting on a joint commitment with a peer recreates a prototypical situation of a second-personal standpoint (Darwall, 2006) where the interaction unfolds between equals and thus involves mutual moral obligations.

A few limitations of our study should be noted. One of them is that because of the complicated nature of the task and especially because we were interested in normative protest between peers, we could not test children younger than 3.5 years of age. It is possible that younger children could already have some understanding of what breaking a joint commitment entails. Perhaps future studies could use simplified paradigms and measures (e.g., nonverbal) to see if younger children could make the distinctions that the children in our study made. On the other hand, testing older children in a paradigm similar to ours could help track the developmental progression of understanding and enforcing collaborative norms. We could predict, for example, that the differences in the type of language the children use in different conditions would become more pronounced with age. Also, additional measures, indexing perspective taking, theory of mind, status in the group, quality of prior relationships between the partners, and so on, could be administered along with this task to explore individual differences in children's propensity to protest against norm violations.

Another potential issue with our study-and a potential theme for further investigation - is the context in which we situated our collaborative task. Recent research has shown that the way in which collaborative rules are learned (i.e., whether rules apply to the self vs. others and whether they are presented in the prescriptive vs. proscriptive form) influences the strength of 4- to 7-year-old children's normative judgments (Riggs \& Young, 2016). One could argue that children may also react to violations of commitment differently in the context where norms and commitments are generated by adults as opposed to a more spontaneous context characteristic of natural peer interactions. In this study, we found that 3-yearold children were able to distinguish and react appropriately to intentional versus unintentional commitment violations in a specific, controlled situation where an adult "handed down" the task, elicited an explicit acknowledgment of joint commitment, and made the interdependent nature of the task clear to the subjects. It is possible that children would have been less indignated and more forgiving of their peers if a violation happened in a less structured environment. Among other variables, the degree to which joint commitment is explicitly communicated between partners (which probably happens infrequently in unstructured peer interactions) could be a factor worthy of future investigation.

\section{References}

Baayen, R. H., Davidson, D. J., \& Bates, D. M. (2008). Mixed-effects modeling with crossed random effects for subjects and items. Journal of Memory and Language, 59, 390-412. doi:10.1016/j.jml.2007.12.005

Brownell, C. A., \& Carriger, M. S. (1991). Collaborations among toddler peers: Individual contributions to social contexts. In L. Resnick, J. Levine, \& S. Teasley (Eds.), Perspectives on socially shared cognition (pp. 365-383). Washington, DC: American Psychological Association.

Carpenter, M., Akhtar, N., \& Tomasello, M. (1998). Fourteen- through 18-month-old infants differentially imitate intentional and accidental actions. Infant Behavior and Development, 21, 315-330. doi:10.1016/S0163-6383 (98)90009-1

Cushman, F., Sheketoff, R., Wharton, S., \& Carey, S. (2013). The development of intent-based moral judgment. Cognition, 127, 6-21. doi:10.1016/j.cognition. 2012.11.008

Darwall, S. (2006). The second-person standpoint: Morality, respect, and accountability. Cambridge, MA: Harvard University Press.

Dobson, A. J., \& Barnett, A. (2008). An introduction to generalized linear models Boca Raton, FL: CRC press.

Dunfield, K. A., \& Kuhlmeier, V. A. (2010). Intentionmediated selective helping in infancy. Psychological Science, 21, 523-527. doi:10.1177/0956797610364119

Fletcher, G. E., Warneken, F., \& Tomasello, M. (2012). Differences in cognitive processes underlying the collaborative activities of children and chimpanzees. Cognitive Development, 27, 136-153. doi:10.1016/j.cogdev.2012.02.003

Forstmeier, W., \& Schielzeth, H. (2011). Cryptic multiple hypotheses testing in linear models: Overestimated 
effect sizes and the winner's curse. Behavioral Ecology and Sociobiology, 65, 47-55. doi:10.1007/s00265-0101038-5

Gilbert, M. (1990). Walking together: A paradigmatic social phenomenon. MidWest Studies in Philosophy, 15, 1-14. doi:10.1111/j.1475-4975.1990.tb00202.x

Göckeritz, S., Schmidt, M. F., \& Tomasello, M. (2014). Young children's creation and transmission of social norms. Cognitive Development, 30, 81-95. doi:10.1016/j. cogdev.2014.01.003

Grafenhain, M., Behne, T., Carpenter, M., \& Tomasello, M. (2009). Young children's understanding of joint commitments. Developmental Psychology, 45, 1430-1443. doi:10.1037/A0016122

Hamann, K., Bender, J., \& Tomasello, M. (2014). Meritocratic sharing is based on collaboration in 3-year-olds. Developmental Psychology, 50, 121-128. doi:10.1037/ a0032965 23688170

Hamann, K., Warneken, F., Greenberg, J. R., \& Tomasello, M. (2011). Collaboration encourages equal sharing in children but not in chimpanzees. Nature, 476, 328-331. doi:10.1038/Nature10278

Hamann, K., Warneken, F., \& Tomasello, M. (2012). Children's developing commitments to joint goals. Child Development, 83, 137-145. doi:10.1111/j.1467-8624.2011. 01695.x 22172281

Hepach, R., Vaish, A., \& Tomasello, M. (2013). A new look at children's prosocial motivation. Infancy, 18, 6790. doi:10.1111/j.1532-7078.2012.00130.x

Ingram, G. P. D., \& Bering, J. M. (2010). Children's tattling: The reporting of everyday norm violations in preschool settings. Child Development, 81, 945-957. doi: 10.1111/j.1467-8624.2010.01444.x

Josephs, M., Kushnir, T., Grafenhain, M., \& Rakoczy, H. (2016). Children protest moral and conventional violations more when they believe actions are freely chosen. Journal of Experimental Child Psychology, 141, 247-255. doi:10.1016/j.jecp.2015.08.002

Koymen, B., Schmidt, M. F. H., Rost, L., Lieven, E., \& Tomasello, M. (2015). Teaching versus enforcing game rules in preschoolers' peer interactions. Journal of Experimental Child Psychology, 135, 93-101. doi:10.1016/j.jecp. 2015.02.005

Mathew, S., \& Boyd, R. (2014). The cost of cowardice: Punitive sentiments towards free riders in Turkana raids. Evolution and Human Behavior, 35, 58-64. doi: 10.1016/J.Evolhumbehav.2013.10.001

Meltzoff, A. N. (1995). Understanding the intentions of others: Reenactment of intended acts by 18-month-old children. Developmental Psychology, 31, 838-850. doi: 10.1037/0012-1649.31.5.838

Michael, J., Sebanz, N., \& Knoblich, G. (2015). The sense of commitment: A minimal approach. Frontiers in psychology, 6. doi:10.3389/fpsyg.2015.01968

Moll, H., Carpenter, M., \& Tomasello, M. (2007). Fourteen-month-olds know what others experience only in joint engagement. Developmental Science, 10, 826-835. doi:10.1111/j.1467-7687.2007.00615.x
Nunez, M., \& Harris, P. L. (1998). Psychological and deontic concepts: Separate domains or intimate connection? Mind $\mathcal{E}$ Language, 13, 153-170. doi:10.1111/1468-0017.00071

ONeill, D. K. (1996). Two-year-old children's sensitivity to a parent's knowledge state when making requests. Child Development, 67, 659-677. doi:10.1111/j.1467-8624. 1996.tb01758.x

Rakoczy, H., Hamann, K., Warneken, F., \& Tomasello, M. (2010). Bigger knows better: Young children selectively learn rule games from adults rather than from peers. British Journal of Developmental Psychology, 28, 785-798. doi:10.1348/026151009X479178

Rakoczy, H., Wameken, F., \& Tomasello, M. (2008). The sources of normativity: Young children's awareness of the normative structure of games. Developmental Psychology, 44, 875-881. doi:10.1037/0012-1649.44.3.875

Riggs, A. E., \& Young, A. G. (2016). Developmental changes in children's normative reasoning across learning contexts and collaborative roles. Developmental psychology, 52, 1236-1246. doi:10.1037/dev0000119

Smith, A. (2013). Moral blame and moral protest. In D. J. Coates \& N. A. Tognazzini (Eds.), Blame: Its nature and norms (pp. 27-48). New York, NY: Oxford University Press.

Strawson, P. F. (1974). Imagination and perception. In P. F. Strawson (Ed.), Freedom and resentment and other essays (pp. 45-65). London: Methuen.

Tomasello, M. (2014). A natural history of human thinking. Cambridge, MA: Harvard University Press.

Tomasello, M., \& Hamann, K. (2012). Collaboration in young children. The Quarterly Journal of Experimental Psychology, 65, 1-12. doi:10.1080/17470218.2011.608853

Tomasello, M., \& Vaish, A. (2013). Origins of human cooperation and morality. Annual Review of Psychology, 64, 231-255. doi:10.1146/Annurev-Psych-113011-143812

Tuncgenc, B., Hohenberger, A., \& Rakoczy, H. (2015). Early understanding of normativity and freedom to act in Turkish toddlers. Journal of Cognition and Development, 16, 44-54. doi:10.1080/15248372.2013.815622

Ulber, J., Hamann, K., \& Tomasello, M. (2015). How 18and 24-month-old peers divide resources among themselves. Journal of Experimental Child Psychology, 140, 228-244. doi:10.1016/j.jecp.2015.07.009

Vaish, A., Carpenter, M., \& Tomasello, M. (2010). Young children selectively avoid helping people with harmful intentions. Child Development, 81, 1661-1669. doi: 10.1111/j.1467-8624.2010.01500.x

Vaish, A., Missana, M., \& Tomasello, M. (2011). Threeyear-old children intervene in third-party moral transgressions. British Journal of Developmental Psychology, 29, 124-130. doi:10.1348/026151010x532888

Warneken, F., Chen, F., \& Tomasello, M. (2006). Cooperative activities in young children and chimpanzees. Child Development, 77, 640-663. doi:10.1111/J.1467-8624.2006.00895.X

Warneken, F., Lohse, K., Melis, A. P., \& Tomasello, M. (2011). Young children share the spoils after collaboration. Psychological Science, 22, 267-273. doi:10.1177/ 0956797610395392 